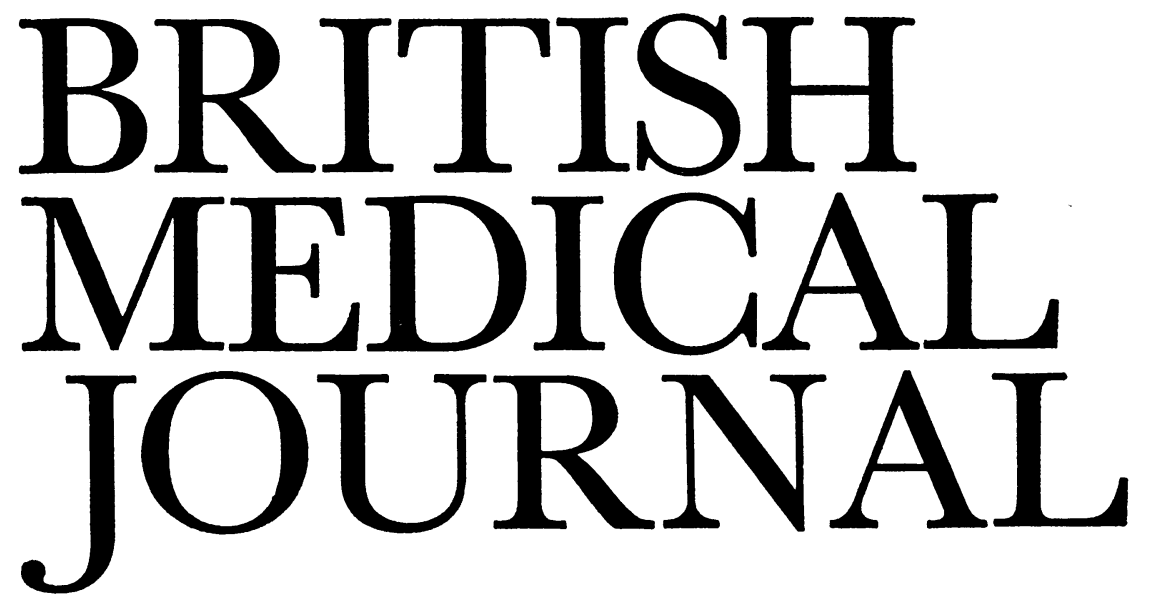

LONDON SATURDAY 19 JUNE 1971

\title{
Postgraduate Training and the Common Market
}

The economic and political consequences of Britain's possible entry into the Common Market are still not clear. Opinion on the medical aspects remains nebulous, confused, and vaguely uneasy, as the discussion at the recent junior members forum (Supplement, p. 140) showed. This may arise partly from the repeated delays in allowing doctors to move about freely within the existing Community and the resulting absence of firm data on that situation, and partly from the size and cemplexity of the problem. But perhaps the chief difficulty is to believe that so drastic a change in the methods of controlling standards could be brought about in such a way.

The Treaty of Rome is an economic instrument and, secondarily, a political one. Medicine comes into it only because an exception could presumably not be made of a single profession, but the degree of its involvement is none the less fundamental, clearly laid down, and inescapable. That being the case, it is indeed hard to explain why no medical authority was created along with the other institutions of the Community, or to condone the absence (still unrectified) of any official medical consultative machinery. The founding fathers behaved in an oddly cavalier fashion towards a subject which they themselves recognized as important for the wide purposes of the treaty.

Fortunately, the framework within which medicine is dealt with is not as inflexible as some of the more pessimistic readings of the treaty have implied, and the foresight and energy of individual members of the profession in Europe have mitigated what might otherwise have been its disastrous effects. The much-quoted Article 57 specifically lays down that so far as medicine is concerned the progressive freeing of restrictions is to be subject to the co-ordination of conditions of practice in the different member States. Harmonization, in the sense of complete congruence of training programmes and conditions of practice, remains an avowed goal for the future and will be essential if coordination is to be achieved without lowering standards. But the legal requirement does not go as far as this, and an additional degree of flexibility is introduced by apparent agreement on a definition of co-ordination which implies something less ambitious than might at one time have been assumed. Some months ago the European Union of Specialists (U.E.M.S.) issued a memorandum ${ }^{1}$ by its president, Dr. P. Pouyaud, summarizing the situation. "Co-ordination," he wrote (here in free translation), "does not mean the enforcement of uniformity or the suppression of national legislation or equalization by adding to what already exists. It means the creation of a structure to fulfil a clearly stated objective-free movement and the right of establishment for doctors within the six countries of the E.E.C., the retention of what is considered in the six countries as the best solution, and the removal of serious discrepancies. The objective so defined is a common organization for free circulation and unimpeded establishment, the part played by co-ordination being limited to what is necessary and sufficient to realize this freedom and overcome any obstacles to it."

This interpretation eases the immediate problem which faces European medicine, and we must therefore be grateful for it. Unfortunately, it also threatens to generate another. The resulting dilemma is only too clearly illustrated in the papers read at the recent meeting in London of the European Association for Internal Medicine (p. 691 of this week's B.M.f.), where a representative of each participating country described his concept of the field of responsibility accepted as appropriate to the specialty and the training programme in force for it. Much encouragement is to be had from the universal search for high standards, but the diversity of attitudes and practices which is otherwise disclosed shows how remote effective harmonization must be. Even to coordinate these diverse patterns is difficult, since each country is producing a specialist whose capabilities interdigitate with other specialties in his homeland, but may not do so abroad.

Co-ordination at the simplest possible level in accordance with Dr. Pouyaud's definition may therefore be a matter of necessity rather than choice, and while we may welcome the simplicity of the definition we may fear also that it is a simplicity enforced by external circumstances on a problem to which no simple solution really exists. We can accept without question that each member country takes pride in its medical standards and that the organization of medical practice in each accords well with national attitudes and conventions, and that to this extent there is common ground throughout Europe. We have also to accept that the common purpose so displayed is accompanied by wide variations in the manner by which the purpose is achieved. The simpler the level of co-ordination, the less closely will these variations be examined. The profession is obviously being called on to strike a delicate balance, and on medical standards compromise is unwelcome to everyone. 
We may be tempted to conclude that Britain's entry into the Common Market would considerably increase the profession's burden of negotiation, inquiry, and debate without commensurate benefit either for the public or for doctors themselves. The conclusion should be avoided, since it is valid only on a narrow view of day-to-day issues. In a larger context, there are substantial, though admittedly indirect, advantages arising from the need to examine long-established conventions and to submit our institutions and our attitudes to criticism by ourselves and by our colleagues in other countries. All over Europe educational standards, the organization of medical practice, and systems of social security are being scrutinized and tested, and ideas on these subjects are crossing national boundaries with the sort of freedom that used to be associated only with scientific and artistic communication. France has undertaken a major revision of its undergraduate curriculum, Italy is reassessing its methods of postgraduate training, and an atmosphere of objectivity and self-criticism is evident in many places where it has for long been absent. In Great Britain many factors have contributed to the transformation that is taking place in postgraduate education, and the prospects of closer European contacts may have done little more so far than add impetus to it. We still lack a yardstick with which to compare the end-products of our system with those of our neighbours. Though we may doubt the validity of such measurements, without them we cannot begin to be objective about the discrepancies that will have to be bridged if unrestricted migration comes into force. Specialist registration has at least provided other countries with a clear measurement of the duration of training, and they are now in the throes of attempting to identify the criteria on which an assessment of quality might be based. Registration is still an emotive subject in Britain, but certification, such as is suggested in the second report of the Joint Committee on Higher Surgical Training, ${ }^{2}$ appears to have been accepted, and is a valuable contribution towards making comparative studies possible.

Clearly, most associations concerned with postgraduate training have given thought to preparing themselves for the situation which may arise. Much more is required, and the nature of the burden involved needs to be understood by the profession at large. The Health Departments are perhaps even more closely concerned. Until now their active participation has been prevented first by the necessary exclusion of government agencies before formal negotiations started, and now by the exclusion of health matters from the subjects for negotiation. It is to be hoped that Government and profession will speak with one voice in the difficult years of adaptation that may lie ahead.

1 Pouyaud, P., Les Fondements de la libre Circulation des Médicins au Sein de la Communauté Economique Européenne. Brussels, Union Européenne des Médicins Specialistes, 1970.

2 Joint Committee for Higher Surgical Training, Second Report. London, Royal College of Surgeons of England, 1971. See B.M.f., 1971, 2,
543 .

\section{Ketamine-A New Anaesthetic}

Ketamine hydrochloride is a new, non-barbiturate, general anaesthetic. Administered intravenously the patient is ready for surgery within a minute; by intramuscular injection induction takes only a little longer. Cardiovascular and respiratory depression are said to be rare; the airway re- mains clear; the laryngeal and pharyngeal reflexes are maintained; and nausea and vomiting are infrequent. ${ }^{1-3}$ The unusual, almost cataleptic, appearance of the patient may be disturbing to those present on the first occasion ketamine is used. The patient looks awake, with his eyes open but with a blank facial expression; the muscle tone is increased, and sometimes there are random, purposeless movements.

As the sole agent ketamine has been used for operations lasting up to six hours, but for such lengthy surgery inhalation agents are usually added. ${ }^{1}{ }^{2}$ Even after a single dose of ketamine the period to full recovery is long, though the patient can soon eat or drink. Hence ketamine is not particularly suitable for outpatient surgery. After repeated doses recovery is progressively more prolonged.

In some patients vivid, brightly coloured dreams of a hallucinatory character occur during recovery, sometimes accompanied by delirium. Their reported incidence differs widely, from less than $5 \%$ of patients in one series, ${ }^{1}$ to over $30 \%$ in another. ${ }^{3}$ Though these dreams are not always disagreeable, sometimes the patient does not wish to have the anaesthetic again. ${ }^{4}$ Dreams are not uncommon after other anaesthetic agents, ${ }^{5}$ but those after ketamine seem different, being more like the effects described after hallucinogenic drugs. These reactions may be minimized by sedative premedication, ${ }^{4}$ by using ketamine only for induction, and especially by ensuring a peaceful, undisturbed period in the recovery room. ${ }^{12}$ This last requirement, on the other hand, tends to cut across standard anaesthetic practice, such as regular estimation of the blood pressure and pulse. Fortunately, children seem to complain of these dreams only rarely and there is no evidence that they suffer any long-term harm, taking into account the difficulty of assessing this in young children. ${ }^{6}$ These unpleasant dreams seem also less common in geriatric patients.

The other main side effect of ketamine is cardiovascular stimulation. Typically, the systolic pressure rises by 25 to $30 \mathrm{~mm} \mathrm{Hg}$ and the heart rate by 10 to 15 beats per minute. This response becomes less pronounced with subsequent doses. ${ }^{2}$ Sometimes this increase in blood pressure and pulse rate may be much more pronounced ${ }^{3}$; therefore systemic hypertension, a history of a cerebrovascular incident, or the presence of heart failure are all considered contraindications to ketamine. An increase in cerebrospinal fluid pressure accompanies the hypertension and its safety in patients with increased intracranial tension has been questioned. ${ }^{7} 8$ Nevertheless, some workers have reported that no serious complication could be related to its use for neuroradiological procedures in children. 910

Since all reports state that the.pharyngeal and laryngeal reflexes are not depressed to any extent, ketamine should be particularly indicated (either as the sole agent or for induction) when there is a risk of pulmonary aspiration from a full stomach, such as exists in the obstetric patient. Nevertheless, the basis for this belief has been shaken by the evidence presented on p. 688 of this week's B.M.F. by P. A. Taylor and R. M. Towey that laryngeal incompetence occurs regularly during ketamine anaesthesia. Perhaps this should have been expected since not only sedatives and all general anaesthetics, but even aging, ${ }^{11}$ reduce the activity of these reflexes. It is clearly wise to prepare the patient as usual for surgery even if ketamine is to be used alone.

It is early yet to be sure of the place of ketamine in anaesthetic practice since it is still on "monitored release" to consultant anaesthetists by the Committee on Safety of Drugs. Already ketamine seems certain to be particularly 